\title{
The role of spirituality in specialist psychiatry: a review of the medical literature
}

\author{
ABR Janse van Rensburg1', CPH Myburgh², CP Szabo', M Poggenpoel ${ }^{3}$ \\ 1Division of Psychiatry, Faculty of Health Sciences, University of the Witwatersrand, Johannesburg, South Africa \\ 2Department of Educational Psychology, University of Johannesburg, Johannesburg, South Africa \\ ${ }^{3}$ Department of Nursing, University of Johannesburg, Johannesburg, South Africa
}

\begin{abstract}
A review of the international medical literature was undertaken on the role of spirituality in the discipline of psychiatry, within the context that a perceived change is taking place in the health care environment in South Africa. Revitalized interest in spirituality was evident from the literature partly because Western societies have, through the migration of people, become more heterogeneous in recent years. The literature concurred that spirituality must be incorporated into the current approach to the practice and training of psychiatry, but within the professional scope of the discipline, while all faith traditions and belief systems should be regarded equally. Beyond South Africa, it is envisaged that the review has implications for the practice of psychiatry in Africa.
\end{abstract}

Keywords: Spirituality; Practice and training; Psychiatry; Medical literature; Qualitative inquiry

Received: $12-03-2012$

Accepted: 04-10-2012

doi: http://dx.doi.org/10.4314/ajpsy.vl6i4.33

\section{Introduction}

An earlier review of the South African medical literature related to the changes in mental health care delivery in South Africa identified a prominent issue regarding African traditional health practice, namely: whether the work done by traditional healers should be regarded as a religion or a modality of psychotherapy. ${ }^{1}$ Some of the literature compared the traditional healer to the Western psychotherapist and considered traditional health practice more as psychotherapy than a religion ${ }^{2-3}$, whilst others referred to African cultural beliefs as being primarily a religious and spiritual practice. ${ }^{4-5}$ Within the context of mental health care delivery, such views require further study and clarification, specifically in terms of the relevance of spirituality to the discipline of psychiatry not only in South Africa, but also in Africa and countries outside of the continent. Several international authors from different countries have reported extensively on the role of spirituality in psychiatry since the 1980's. The countries include: the Unites States ${ }^{6-9}$, Canada ${ }^{10-11}$, the United Kingdom (UK) ${ }^{12-15}$, the Netherlands ${ }^{16-18}$, Brazil ${ }^{19-20}$ and Australia. ${ }^{21-22}$ Such content related to a range of issues:

- A systematic analysis of quantitative research on religious variables by Larson et al, found in four psychiatric journals between 1978 and 1982 revealed a considerable lag in the diffusion of academic knowledge and skills to evaluate religion in psychiatric theory, concept and methodology. ${ }^{6}$ Larson et al., also reviewed the Glossary for Technical Terms of the revised third edition of the Diagnostic and Statistical Manual (DSM-III-R) for its references to religion and concluded that the high rate of illustrative case examples of psychopathology that involve religion, indicates cultural insensitivity in interpreting religion. ${ }^{7}$

- Koenig et al., provided "a rebuttal to skeptics" on religion, spirituality and medicine ${ }^{8}$ and in several other editorials, he provided overviews to physicians on religion, spirituality and medicine. ${ }^{23-25}$

- Andreasen, as editor of the American Journal of Psychiatry at the time, stated in 2001: "We must practice and preach the fact that psychiatrists are physicians of the soul as well as of the body."26 
- Baetz et al., reported on the association between spiritual and religious involvement and depressive symptoms in a Canadian population. ${ }^{10}$ Subsequent research for lifetime, l-year incidence and past psychiatric disorders found that higher worship frequency was associated with lower odds of psychiatric disorders. ${ }^{11}$

- Sims from the UK, used the term "cure of souls" as point of departure and considered how the three groups: psychiatrists, religious people and patients, would differ in their understanding of its meaning. ${ }^{12} \mathrm{He}$ quoted Bhugra, who explained the problem as two next door neighbors: ". .. (the) two neighbours (psychiatry and religion)... should be on very good terms, but, due to a long-forgotten episode over the niggle about the size of the fence, have fallen out. . ."27

- Culliford set a definition of spirituality within the context of the World Health Organization's quality of life (WHO$\mathrm{QOL}$ ) domains and the facets proposed for a WHO-QOL Spirituality, Religious and Personal Beliefs (SRPB) module. ${ }^{13}$ While referring to an often quoted definition of spirituality by Murray and Zentner ${ }^{28}$, he identified a new paradigm of research, moving beyond positivism, that includes qualitative research approaches such as participant observation, phenomenology and unstructured in-depth interviews. ${ }^{13}$

- Moreira-Almeida provided an overview of spirituality and psychiatry in a Brazilian context. ${ }^{19} \mathrm{He}$ and Koenig discussed the WHO-QOL SRPB that was used in a cross-cultural study in 18 countries, while considering the attributes of an ideal inclusive, trans-culturally validated measurement of religiousness and spirituality. ${ }^{20}$

- D'Souza and Rodrigo described an approach to "spiritually augmented cognitive behavioral therapy' (SACBT), which was developed and tested by a multidisciplinary team involving various clinical professionals, members of the hospital's pastoral team and an indigenous elder. ${ }^{22}$

- Robert Cloninger is, for example, also well known for the incorporation of spirituality in the existing approach to specialist psychiatric and psychotherapeutic practice. ${ }^{29}$ His widely adopted theory of personality introduced a broadened and integrative approach to the psychiatric assessment, care and management of personality problems. ${ }^{30}$ His theory involves four temperament dimensions and three character dimensions. The three character dimensions include self-directedness, cooperativeness and selftranscendence. ${ }^{31-32}$

It was against this background, where spirituality was observed to play an increasing role in secular fields such as health, mental health and psychiatry that a review of the international medical literature was undertaken.

\section{Method}

Ethics clearance for the research component of this study which involved psychiatrist interviews - was granted by the Human Research Ethics Committee of the University of the
Witwatersrand in 2007. The literature review as part of that study was conducted with the support of staff from the University of Witwatersrand's Faculty of Health Sciences' library, using the phrase "spirituality and psychiatry". The initial search covered the following databases: African Digital Library, Biblioline, BioMed Central, BMJ Clinical Evidence, Cochrane Library, Sabinet, Cudos, DOAJ, Ebsco Host, First Search OCLC, Thomson Gale, Ovid SP, JStor, MDConsult, Nexus, Oxford Scholarship Online, ProQuest, Psychiatry Online, PubMed, SAePublications, SAGE Premier Online, Science Direct, Scopus, Springer and Wiley Interscience. The search yielded 520 references. A literature review reference list was compiled from this initial database search of journal articles regarded as the most important references on: spirituality and practice related issues; spirituality and training; and users' perspectives on the role of spirituality. References that were excluded were those for which only abstracts were available, duplications, references not primarily covering psychiatry, or those only covering related areas such as quality of life. A descriptive record of each selected article was entered into an Excel spreadsheet according to a structured data sheet which included the following variables: record number; type of publication; country published; year; first second and third authors; title; journal reference; origin of author; text scope; method; and themes.

A thematic content analysis was made through the open coding of data. Open coding refers to the creation of certain categories pertaining to certain segments of text and is aimed at expressing data and phenomena in the form of concepts. Themes were not identified in advance, but derived from the interview and literature data.

\section{Results}

A total of 255 literature records were included in the formal review, of which there were: books ( $n=7)$; chapters in books $(n=3)$; editorial comments $(n=37)$; journal articles ( $n=202) ;$ and letters and reviews $(n=6)$. A significant increase of literature records on the topic of spirituality and psychiatry over the past 20 years was noted. From 1986 to 1999 there were 39, whereas from 2000 to 2009, there were 216. Countries of origin of the literature records or authors were: United States ( $n=190)$; United Kingdom ( $n=15)$; Australia ( $n=13)$; Brazil ( $n=8)$; Canada ( $\mathrm{n}=12)$; from Europe $(\mathrm{n}=6)$ - including the Netherlands, Germany, Norway and Switzerland; and other ( $\mathrm{n}=1 \mathrm{l}$ ) - including China, Croatia, India, Israel, Nigeria, South Africa and South Korea.

Most literature records ( $\mathrm{n}=204$ ) were qualitative investigations or essay-type of overviews and commentaries and of these records, most were essays or commentaries ( $\mathrm{n}=159)$, while others were literature reviews $(n=22)$, conducted action research $(n=10)$, or used focus group discussions ( $\mathrm{n}=2)$, semi-structured, $(n=7)$ or unstructured interviews $(n=5)$. A total of 51 inquiries were quantitative in nature, using questionnaires in surveys ( $n=45)$, or structured scales of measurement $(\mathrm{n}=6)$. 
In terms of themes identified from the literature, six concept categories were finally synthesized from the integrated data (Table I), in terms of which the literature content was summarized:

(1) Orientation in terms of spirituality and religion in psychiatry;

(2) Reality of spirituality and religion for practitioners and users;

(3) Routine assessment of spirituality and religion in psychiatry;

(4) Training of spirituality in psychiatry;

(5) Scope and boundaries of spirituality in psychiatry;

(6) Referral and collaboration on spirituality in psychiatry.

\section{Orientation in Terms of Spirituality and Religion in Psychiatry}

While psychiatrists are traditionally less inclined to be religiously or spiritually orientated than their clients or colleagues in other specialties, they are reported to be more comfortable and to have more experience in addressing religious and/or spiritual concern. ${ }^{12,33-37}$ This was also observed with regard to family practitioners, where participants in semi-structured interviews affirmed a role for family practitioners, although they differed in being comfortable addressing spiritual issues in their practice. ${ }^{38-40}$ Psychiatrists do not necessarily have to have personal spiritual beliefs or convictions themselves, but as clinicians, they have to understand the importance thereof, as well as have skill and knowledge to make accurate assessments and appropriate referrals.

Many authors have referred to the significant increase over the past two decades in focus, research attention and publications in the field of spirituality and/or religion in general but also in particular regarding health, mental health and psychiatry. ${ }^{41-45}$ Tracking the history of the split between religion and psychiatry over the past 200-300 years, authors referred to Freud's negative views of religion and the influence of his teaching on psychiatry in the 20th century.46 In addition to the historic split ("divorce") between spirituality/religion and psychiatry ${ }^{46-49}$, a recent process of reconciliation ("rapprochement") has been observed over the past two decades in the long-divided healing traditions of science and medicine on the one hand and spirituality, and/or religion on the other. ${ }^{50-53}$

The extent to which spirituality and religion has currently been (re-)considered and (re-) incorporated into the practice and training of specialist psychiatry is reflected by the history of its incorporation into the diagnostic classification systems, in particular the Diagnostic and Statistical Manual (DSM). Authors mentioned how the concepts were considered first in the DSM-III ${ }^{67}$, where religion was still used in culturally insensitive examples of psychopathology only, and then in the DSM-IV, as a separate category that may be a focus of clinical attention, but which is not regarded as psychopathology. ${ }^{54-56} \mathrm{~A}$

\section{Table I: Concept categories from literature content}

\begin{tabular}{|c|c|}
\hline Categories & Subcategories \\
\hline 1. Orientation in terms of spirituality and religion in psychiatry & $\begin{array}{l}\text { 1.1 Own view of and attitude towards spirituality } \\
\text { 1.2 Academic view of medical science and of pa } \\
\text { 1.3 Providers' perspectives } \\
\text { 1.4 Principles in practice: history and philosophy } \\
\text { 1.5 Definition of spirituality and religion; concepts }\end{array}$ \\
\hline 2. Reality of spirituality and religion for practitioners and users & $\begin{array}{l}\text { 2.1 Extended model of care: "bio-psycho-social } \\
\text { 2.2 Principles in practice: approach } \\
\text { 2.3 Users' perspectives }\end{array}$ \\
\hline 3. Routine assessment of spirituality and religion in psychiatry & $\begin{array}{ll}\text { 3.1 } & \text { Need assessment } \\
\text { 3.2 } & \text { Communication and appropriate interventior } \\
\text { 3.3 Liaison and referral } \\
\text { 3.4 } \\
\text { 3.5 } & \text { Assesentation and symptoms } \\
\end{array}$ \\
\hline
\end{tabular}

4. Training of spirituality in psychiatry

4.1 Understanding of spirituality and its role in mental health care

4.2 Didactic teaching on spirituality and religious faith traditions

4.3 Approach towards spirituality and religion in psychiatry

4.4 Personal growth, professional development and competency

5. Scope and boundaries of spirituality in psychiatry

6. Referral and collaboration on spirituality in psychiatry
5.1 Ethics of spirituality in psychiatric practice; Principles in practice: ethics

5.2 Continued education and peer review

5.3 Psychotherapy

6.1 Facilitating appropriate referral and intervention for individual users

6.2 Information sharing and mutual awareness between disciplines

6.3 Addressing stigmatization of users with psychiatric conditions

6.4 Religious-spiritual traditions

6.5 Spiritual professionals' perspectives 
particular tone and direction about how the role of spirituality should be regarded in the psychiatric profession was set by prominent international academics. ${ }^{57-58}$ As the causes and manifestation of psychopathology are more deeply connected to culture and spirituality, Fabrega calls for the restoring of cultural psychology to its rightful place in the taxonomy, nosology and rationale of systems of diagnoses. ${ }^{57}$

According to Carr the social function of spirituality has to be recognized, as well as the internal validation of individual spirituality. ${ }^{59}$ Rhi used a conceptualization of the traditional shaman as "prototype" of healer to contrast it with the onesided materialistic, mechanistic view of patients - currently pervading modern medicine - that only chemically treats symptoms of disease. ${ }^{60}$ Reports on the different official policy positions of the medical profession and the discipline of psychiatry in different countries, provided some perspective on the process, time and resources that were invested to achieve acknowledgement of the role that spirituality plays in the lives of people and to respond to it appropriately as a profession. ${ }^{14,15}$

No single perspective on the definition of spirituality seems to dominate in the postmodern culture. Multiple perspectives seem to exist. 13,26,28,61-67 Attributes of spirituality that were described included: "a journey, transcendence, community, mystery of creation, transformation" "68; "the meaning and purpose of life, transcendence, connection with others and energy"67; "relationships with others in faith community"69; "inner realm reacting with the transcendental" 44 ; and "a person's attempt to make sense of the world". ${ }^{70}$ Considering the definition of the construct religion, authors regarded religion to have attributes such as: "organized systems of principles, beliefs, rituals, practices, related symbols" 69 ; "the outer realm reacting with the world" 44 ; and "beliefs, practice and rituals related to the sacred or the "numinous". ${ }^{62}$ The overlap between the two constructs included the search for the sacred and the process of establishing meaning ${ }^{71}$, and the difference, that spirituality includes religion and relations with others, but is not limited by organized religion. ${ }^{70}$

Dein commented that the use of a Western definition of religion may not be useful in a cultural comparison with nonWestern traditions. ${ }^{72}$ Comments were made about the potential of religious institutions to become oppressive and divisive once contact with spiritual content has been lost. Cognizance should also be taken of other healing traditions, including Indian, Chinese and different indigenous perspectives. ${ }^{73}$ Re-introduction of spirituality into health, mental health and psychiatry would make the field more ethical, caring and compassionate. ${ }^{74}$

\section{Reality of Spirituality and Religion for Practitioners and Users}

Gilbert outlined the discourse on spirituality and mental health over past decades and showed how it changed from focus on issues around "race" and "color" in the 1950's and 60 's to religion in the present time. ${ }^{15}$

An approach towards considering the reality of spirituality in specialist psychiatry, would therefore have to first achieve clarity about the nature and definition of the boundary that exists between two adjacent, "neighboring" territories. ${ }^{12,27}$ "Turf battles" between these spiritual professionals and health workers would be another matter which would benefit from clear guidelines and training in this regard. ${ }^{12}$ Removal of such perceived tensions between patients' spiritual advisers and their psychiatrists may in itself allow patients to be more open about matters concerning their mental health and therefore may probably be more compliant with their psychiatric treatment.

Instances where patients themselves are less comfortable with religious advice and therefore search out the advice of psychiatrists and psychotherapists instead ${ }^{52}$, may, according to Sperry, place a bigger onus on the latter two disciplines to provide some form of spiritual directive as "substitute secular priests". ${ }^{75}$ According to Fallot, consumers noted both the potentially supportive and burdensome roles of religions and spiritual recovery, while professionals reported both hope for, and discomfort with, these domains. ${ }^{76}$ Brooks and Koenig and Puchalski et al., reported on the need for programs, facilities and service providers to make allowance for spirituality in terms of infrastructure, budget and environment for patients to express their spirituality and religiosity. ${ }^{77-78}$

Positive associations between spirituality (salience) and better health outcomes were identified from research reports and were used by some authors to motivate the importance of spirituality's role in clinical settings. ${ }^{79-82}$ A positive effect was also reported on medical conditions such as cardiovascular disease, hypertension, stroke and other stress and life style related conditions. ${ }^{83-84}$ The psychopathological symptoms that apparently benefitted from spiritual and/or religious involvement, included: depression ${ }^{10}$; suicidality ${ }^{85}$; anxiety; and substance abuse. ${ }^{86-88}$ Explanations for the positive influence of spirituality and/or religion, included that religious belief provides a positive worldview which gives experiences meaning and which also acts as an agent of social control.

Rumbold, referring to Sulmasy, discussed the principles of spirituality and psychiatry in practice. ${ }^{89-90}$ On a clinical level, approaches to including spirituality and religion in routine clinical history taking, in "spiritually augmented cognitive behavioral therapy" and the use of more established models for family medicine practice were discussed. ${ }^{21,91}$ Puchalski described a model ("FICA") that refers to faith and belief (F), importance and influence (I), community (C) and address or action (A)..$^{92}$ The place of spirituality in psycho-social rehabilitation was also reviewed, including: conducting spiritual assessments; discussion groups; facilitating linkages to faith communities and spiritual resources. ${ }^{76-93}$

A theoretical model was described by Koenig to illustrate the complex pathways in which religion may influence physical health. ${ }^{94-96}$ His model demonstrates the complex influence of religion on physical health, considering genetics, childhood training and other social influences. Other theorists such as Cloninger, Vaillant, Anandarajah and Flannelly also presented more elaborate theories on the reality of spirituality for psychiatry. Cloninger's Temperament and Character Inventory (TCI) based on his theory of personality with different temperament and character dimensions, has been part of the teaching curriculum in psychiatry for many years. ${ }^{29,31}$ Vaillant used arguments pertaining to genetic evolution and language development, to propose the maturation of human spirituality as the "third" human evolutionary process. ${ }^{97-98} \mathrm{He}$ suggested that three evolutions could be identified, the genetic (Darwinian) evolution, a 
cultural evolution (mediated by the development of language) and then the maturation of human spirituality. Anandarajah described two multidimensional models for spirituality applicable across culture and belief systems that could be used for patient care, education and research. ${ }^{99}$ Flannelly et al., discussed the ideas contained in their "ETAS"

(Evolutionary threat assessment systems) theory, referring to how brain mechanisms that evolved to assess environmental threats underlie psychiatric disorders. ${ }^{100-101}$

Actual and potential service users have indicated in studies that they regard the role of spirituality and religion in general and in health matters as very important. ${ }^{10,11,33-34,65,102}$ The role of spirituality and religion was also regarded as important in a child and adolescent setting ${ }^{70,103-107}$ as well as for the elderly and end of life/terminal illness scenarios. ${ }^{108-112}$

\section{Routine Assessment of Spirituality and Religion in Psychiatry} Spirituality and religion may affect aspects of the presentation and symptoms of illness in different clinical scenarios. ${ }^{13-115}$ To attend to the clinical needs of certain population groups, an understanding of how a religious or faith tradition may influence the presentation of patients is important, according to Carter. ${ }^{116}$ It is well established how spirituality, for example, can influence the particular content of psychotic symptoms. ${ }^{25,117}$

It is a necessary skill to be able to differentiate between pathological and non-pathological religious involvement. Reviews of the literature over the years have covered the influence of religion and spirituality in a variety of psychiatric conditions such as mood and anxiety ${ }^{30-34,118-121}$, psychosis and schizophrenia ${ }^{117,122-125}$, alcohol and drug abuse. ${ }^{86-88}$ Commitment to tribal cultural spirituality among American Indians was found to be a protective factor in suicide attempts ${ }^{85}$, while fewer depressive symptoms in religious subjects were found in Canada. ${ }^{10,11}$

Clinical assessment and objective measuring of spirituality and religiousness also translate to be a research concern. Moreira-Almeida and Koenig addressed the issue of measuring and comparing variables with reference to the official World Health Organization (WHO) tool - the WHO Quality of Life Measure for assessment of spirituality, religion and personal beliefs (WHO-QOL SRPB). King et al. developed and tested a 20-item questionnaire that goes beyond conventional religious beliefs for use in psychological and health research. ${ }^{126}$ Katerndahl and Oyiriaru developed and validated an instrument for each of the dimensions of a biopsycho- social-spiritual model ${ }^{127}$, while Koenig warned against domains correlating with positive psychological aspects, which may result in a tautological comparison. ${ }^{62}$

\section{Training of Spirituality in Psychiatry}

Undergraduate curricula in the United States have been developed following requirements from the national accreditation body. ${ }^{128-131}$ For psychiatric residents, spirituality as a potential source of higher functioning for the patient, must be included in training programs. ${ }^{78,132-133}$ Myths about religion and psychiatry should be dispelled and perceptions of young psychiatrists, that an interest in spirituality and religion should be avoided for fear of a negative impact on their careers, should be corrected. ${ }^{134-135}$ Ways of introducing courses in spirituality in medical curricula and psychiatric residency programs in the United States and Canada have been well documented. ${ }^{136-137}$

\section{Scope and Boundaries of Professional Specialist Psychiatric Practice}

Defining boundaries, domains and roles will also have to result in the drafting of practical, ethical and professional guidelines for psychiatry and related disciplines. ${ }^{138}$ What must be regarded as part of the scope of professional psychiatry should be clear and must be congruent with the general ethical principles that guide clinical practice. ${ }^{139}$ Although the role of spirituality should be considered in clinical settings, the psychiatrist is not regarded as primary provider of spiritual interventions and guidance for patients. 48,140 Appropriate knowledge and skills to assess the (positive and negative) role of spirituality and religion, or the lack thereof, should be facilitated. What would constitute inappropriate spiritual interventions by psychiatrists, while involving third party funders for instance, will have to be identified and monitored. ${ }^{141}$ Verification between training curricula, proven competency and ongoing professional conduct and practice is essential, while greater patient empowerment through autonomy and self-determination should be achieved. ${ }^{142}$

\section{Referral and Collaboration between Psychiatrists and Spiritual Professionals}

A sociological and anthropological understanding of spirituality and religions should be achieved. The unique approach of each tradition relevant to health, mental health and clinical medicine should be understood and explored. 60,68,72,74,85,116,143-146 Literature referring to a "spiritual professional" routinely described a resident Christian minister of religion in a hospital with experience and training in the pastoral care of patients with medical conditions.

Views and experiences of professional spiritual workers on the role of spirituality in health and psychiatry should be established and taken into consideration. ${ }^{147-152}$ As a proper exploration of this theme represents an additional review of the non-medical literature as well, it was regarded to be beyond the scope of this inquiry. ${ }^{153-154}$

\section{Discussion}

A limitation of this explorative qualitative literature review that must be noted is that it should not be regarded as a comprehensive or systematic, "stand-alone" review of all the medical literature available. Its findings should also not be generalized beyond this particular sample of medical and psychiatric literature. In addition, an exploration of the bodies of nursing and allied professions' literature, of sociology, anthropology and of the religious literature was, for example, also beyond the scope of this review.

The discussion, however, about the validation of the roles of spirituality and religion and how this should be addressed in health care provision, and also as part of routine psychiatric assessment and intervention, has become a discourse of increasing importance in the international medical literature over the past two decades. From the literature, it became apparent that "mindfulness" towards spirituality, should be facilitated and that spirituality should be incorporated in the approach to specialist psychiatric practice and training, although in practical clinical and academic settings, this 
discourse on the role and importance of spirituality, remains in many instances still largely marginalized. In view of the growing body of research on the relationship between religion and health, Krause recently presented a conceptual model to obtain a more coherent view of this field of research. ${ }^{155}$ This model adopts a framework similar to Maslow's hierarchy of needs, including the need for selftranscendence, the need for church attendance, the need for sociality, the need for control, the need for meaning and the need for health. ${ }^{156}$ The basic premise of the model is that there is a logical temporal ordering among these needs that are satisfied by religion, such that the satisfaction of one need sets the stage for the satisfaction of the need that follows.

\section{Conclusion}

In the South African context, the promulgation of the Traditional Health Practitioner's Act no. 35 of 2004, has become an important precipitant for the local review of the place of culture and religion/spirituality in secular areas such as health, mental health and psychiatry. ${ }^{157}$ This recognizes that African traditional practice consists of a significant religious and spiritual component, in addition to just being part of people's cultural background. The literature concurred that if the role of spirituality is to be considered in the approach to health and clinical care, it should be done within clear professional boundaries, and with a perspective that can accommodate religious traditions equally. In the public sector domain, no preference for one particular tradition should be given over another, as a result of a practitioner or a dominant group being from the one tradition or the other. To build up relationships of mutual trust and understanding will require training and health education initiatives aimed at psychiatric practitioners, their patients and students and at the spiritual professionals to whom their patients may choose to be referred.

\section{Acknowledgements}

This research was supported by the Faculty of Health Sciences of the University of the Witwatersrand, Johannesburg by awarding two individual grants during 2009 and 2010 to the first author.

\section{References}

1. Janse van Rensburg ABR. A changed climate for mental health care delivery in South Africa. African Journal of Psychiatry 2009;12(2):157-165

2. Bührmann MV. Western Psychiatry and the Xhosa Patient. South African Medical Journal 1977; 51:464-466.

3. Berg A. Ancestor Reference and Mental Health in South Africa. Transcultural Psychiatry 2003;40(2):194-207.

4. Edwards SD, Grobbelaar PW, Makunga NV, Sibaya PT, Nene LM,Kunene ST, Magwasa AS. Traditional Zulu Theories of Illness in Psychiatric Patients, Journal Social Psychology 1983;121:213-221.

5. Griffiths JA, Cheetham RWS. Priests before healers - An appraisal of the isangoma or isanusi in Nguni society. South African Medical Journal 1982;62:959-960.

6. Larson DB, Pattison EM, Blazer DG, Omran AR, Kaplan BH Systematic analysis of research on religious variables in four major psychiatric journals, 1978-1982. The American Journal of Psychiatry 1986;143(3):329-334.

7. Larson DB, Thielman SB, Greenwold MA, Lyons JS, Post S, Sherrill
$K A$, et al. Religious content in the DSM-III-R glossary of technical terms. The American Journal of Psychiatry 1993;150(12):1884-1885.

8. Koenig HG, Idler E, Kasl S, et al. Religion, spirituality, and medicine: a rebuttal to skeptics. International Journal of Psychiatry in Medicine 1999; 29(2):123-131

9. Koenig HG, MCCullough ME, Larson DB. Handbook of Religion and Health. New York: Oxford University Press; 2001.

10. Baetz M, Griffin R, Bowen R, Koenig HG, Marcoux E. The association between spiritual and religious involvement and depressive symptoms in a Canadian population. The Journal of Nervous and Mental Disease 2004;192(12):818-822.

11. Baetz M, Bowen R, Jones G, Koru-Sengul T. How spiritual values and worship attendance relate to psychiatric disorders in the Canadian population. Canadian Journal of Psychiatry 2006; 51 (10):654-661.

12. Sims $A$. The cure of souls: psychiatric dilemmas. International Review of Psychiatry 1999;11 (May-Aug):97-102.

13. Culliford L. Spiritual care and psychiatric treatment: an introduction Advances in Psychiatric Treatment 2002;8:249-261.

14. Gilbert PD. Engaging hearts and minds... and the spirit. Journal of Integrated Care 2007;15(4):20-27.

15. Gilbert PD. Spirituality and mental health: a very preliminary overview. Current Opinion in Psychiatry 2007;20:594-598.

16. Verhagen PJ. (ed.) Religieuze psychopathologie. Tilburg: KSGV; 2007.

17. Glas G, Spero MH, Verhagen PJ, van Praag HM. (eds.) Hearing visions and seeing voices. Springer; 2007.

18. Zock, T.H. \& Glas, G. (eds.). Religie in de psychiatrie. Tilburg: KSGV; 2001.

19. Moreira-Almeida A. Spirituality and health: past and future of a controversial and challenging relationship. Revista de Psiquiatria Clínica 2007;34(Supplement no. 1):3-4.

20. Moreira-Almeida A, Koenig HG. Retaining the meaning of the words religiousness and spirituality: a commentary on the WHOQOL SRPB group's "a cross-cultural study of spirituality, religion, and personal beliefs as components of quality of life". Social Science and Medicine 2006; 63(4):843-845.

21. D'Souza R. Incorporating a spiritual history into a psychiatric assessment. Australasian Psychiatry 2003;1 1(1):12-15.

22. D'Souza RF, Rodrigo A. Spiritually augmented cognitive behavioural therapy. Australasian Psychiatry 2004;12(2):148-152.

23. Koenig HG. Religion, spirituality, and medicine: application to clinical practice. Journal of the American Medical Association 2000; 284(13):1708

24. Koenig HG. Taking a spiritual history. Journal of the American Medical Association 2004;291 (23):2881.

25. Koenig HG. Religion, spirituality and psychiatry: a new era in mental health care. Revista de Psiquiatria Clínica 2007; 34(Supplement no 1):5-7.

26. Andreasen NC. Diversity in psychiatry: Or, why did we become psychiatrists? American Journal of Psychiatry 2001;158(5):673-675.

27. Bhugra D. Psychiatry and Religion: Context, Consensus and Controversies. London: Routledge; 2006.

28. Murray RB, Zentner JP. Nursing concepts for health promotion. London: Prentice Hall; 1989.

29. Cloninger CR, Svrakic DM. Personality Disorders. In: Sadock BJ, Sadock V. (eds.) Comprehensive Textbook of Psychiatry (7th edn.). Philadelphia: Lippencott, Williams and Wilkens; 2000: pp.17231764.

30. Cloninger CR, Svrakic DM, Przybeck TR. Can personality assessment predict future depression? A twelve month follow-up of 631 subjects. Journal of Affective Disorders 2006; 92:35-44. 
31. Cloninger $C R$. The science of well-being: an integrated approach to mental health and its disorders. World Psychiatry 2006;5(2):71-76.

32. Cloninger CR. Feeling Good: The Science of Well Being. New York: Oxford University Press; 2004

33. Baetz M, Griffin R, Bowen R, Marcoux G. Spirituality and psychiatry in Canada: psychiatric practice compared with patient expectations. Canadian Journal of Psychiatry 2004; 49(4):265-271.

34. Baetz M, Larson DB, Marcoux G, Jokic R, Bowen R. Canadian psychiatric inpatient religious commitment: An association with mental health. Canadian Journal of Psychiatry 2002; 47(2):159-166.

35. Curlin FA, Lawrence RE, Odell S, Chin MH, Lantos JD, Koenig HG et al. Religion, spirituality, and medicine: psychiatrists' and other physicians' differing observations, interpretations, and clinical approaches. The American Journal of Psychiatry 2007; 164(12):1825-1831.

36. Curlin FA, Odell SV, Lawrence RE, Chin MH, Lantos JD, Meador KG, Koenig HG. The relationship between psychiatry and religion among U.S. physicians. Psychiatric Services 2007; 58(9):1193-1198.

37. Curlin FA, Sellergren SA, Lantos JD. Chin MH. Physicians' observations and interpretations of the influence of religion and spirituality on health. Archives of Internal Medicine 2007; 167(7):649-654

38. Ellis MR, Campbell JD, Detwiler-Breidenbach A, Hubbard DK. What do family physicians think about spirituality in clinical practice? Journal of Family Practice 2002; 51 (3):249-254

39. Monroe MH, Bynum D, Susi B, Phifer N, Schultz L, Franco M, et al. Primary care physician preferences regarding spiritual behaviour in medical practice. Archives of Internal Medicine 2003, 163(22):2751-2756.

40. Peach HG. Religion, spirituality and health: how should Australia's medical professionals respond? Medical Journal of Australia 2003; 178(2):86-88.

41. Bathgate D. Psychiatry, religion and cognitive science. Australian and New Zealand Journal of Psychiatry 2003; 37(3):277-285.

42. Blanch A. Integrating Religion and Spirituality in Mental Health: The Promise and the Challenge. Psychiatric Rehabilitation Journal 2007; 30(4):251-260

43. D'Souza R. The importance of spirituality in medicine and its application to clinical practice. The Medical journal of Australia 2007; 186(10) Supplement: S57-S59.

44. D'Souza R, George K. Spirituality, religion and psychiatry: its application to clinical practice. Australasian Psychiatry 2006; 14(4):408-412

45. Lakoff G, Johnson M. Philosophy in the flesh: the embodied mind and its challenge to western thought. New York: Basic, 1999.

46. Koenig HG. Religion and medicine I: historical background and reasons for separation. International Journal of Psychiatry in Medicine 2000; 30(4):385-398.

47. Bartocci G, Dein S. Religion and mental health. In: Bhui, K. \& Bhugra, D. (eds.) Cultural and mental health, a comprehensive textbook, pp. 47-54. London: Edward Arnold, 2007.

48. Daaleman TP. Religion, spirituality, and the practice of medicine. Journal of the American Board of Family Practitioners 2004; 17(5):370-376

49. Powell A. Spirituality and science: a personal view. [Editorial] Advances in Psychiatric Treatment 2001; 7:319-321.

50. Halasz G. Can psychiatry reclaim its soul? Psychiatry's struggle against a de-spirited future. Australasian Psychiatry 2003; 11 (1):911 .

51. Sims, A. Mysterious ways: Spirituality in British Psychiatry in the 20th Century. 2003; [online] Available from
http://www.rcpsych.ac.uk/pdf/Andrew\%20Sims\%201.11.03\%

20Mysterious\%20Ways\%20-

\%20Spirituality\%20and\%20British\%20Psychiatry\%20in\% 20the\%2020th\%20Century.pdf.; [Accessed 9/11/2009].

52. Sperry L. Spirituality and psychiatry: Incorporating the spiritual dimension into clinical practice. Psychiatric Annals 2000; 30(8):518523.

53. Turbott J. Religion, spirituality and psychiatry: Steps towards rapprochement. Australasian Psychiatry 2004;12(2):145-147.

54. Lukoff D, Lu F, Turner R. From spiritual emergency to spiritual problem: the transpersonal roots of the new DSM-IV category. The Journal of Humanistic Psychology 1998; 38(2):21-30.

55. Turner RP, Lukoff D, Barnhouse RT, Lu FG. Religious or spiritual problem. A culturally sensitive diagnostic category in the DSM-IV. The Journal of Nervous and Mental Disease 1995; 183(7):435-444

56. Scott, S, Garver S, Richard J, Hathaway WL. Religious issues in diagnosis: the V-code and beyond. Mental Health, Religion and Culture 2003; 6(2):161-173.

57. Fabrega H. Culture, spirituality and psychiatry. Current Opinion in Psychiatry 2000; 13(6):525-530.

58. Leon CA, Tasman A, Lopez-Ibor JJ, Wig NN, Sims A, Mezzich JE et al. Culture, spirituality and psychiatry. [Comments] Current Opinion in Psychiatry 2000; 13(6):531-534.

59. Carr W. Some reflections on spirituality, religion and mental health. Mental Health, Religion and Culture 2000; 3(2):1-12.

60. Rhi BY. Culture, spirituality, and mental health. The forgotten aspects of religion and health. The Psychiatric Clinics of North America 2001; 24(3):569-579.

61. Greasley P, Chiu LF, Gartland RM. The concept of spiritual care in mental health nursing. Journal of Advanced Nursing. 2001;33(5):629-637.

62. Koenig HG. Research on religion, spirituality, and mental health: a review. Canadian Journal of Psychiatry 2009; 54(5):283-291.

63. Meador KG, Koenig HG. Spirituality and religion in psychiatry practice: parameters and implications. Psychiatric Annals 2000; 30(8):549-555.

64. Pembroke NF. Appropriate spiritual care by physicians: a theological perspective. Journal of Religion and Health 2008; 47(4):549-559.

65. Russinova Z, Cash D. Personal Perspectives about the Meaning of Religion and Spirituality among Persons with Serious Mental Illnesses. Psychiatric Rehabilitation Journal 2007; 30(4):271-284.

66. Sesanna L, Finnell D, Jezewski MA. Spirituality in Health related literature. Journal of Holistic Nursing 2007; 25(4):252-262.

67. Waldfogel S. Spirituality in medicine. Primary care 1997; 24(4):963976.

68. Lapierre L. A model for describing spirituality. Journal of Religion and Health 1994; 33(2):153-161.

69. Josephson AM, Dell ML. Religion and spirituality in child and adolescent psychiatry: A new frontier. Child and Adolescent Psychiatric Clinics of North America 2004; 13(1):1-15.

70. Bienenfeld D, Yager J. Issues of spirituality and religion in psychotherapy supervision. The Israel Journal of Psychiatry and Related Sciences 2007; 44(3):178-186.

71. Yuen EJ. Spirituality, religion and health. [Editorial] American Journal of Medical Quality 2007; 22: 77-79

72. Dein S. Spirituality, psychiatry and participation: A cultural analysis. Transcultural Psychiatry 2005; 42(4):526-544

73. Verghese A. Spirituality and mental health. Indian Journal of Psychiatry 2008; 50(4):233-237.

74. Chattopadhyay S. Religion, spirituality, health and medicine: why 
should Indian physicians care? Journal of Postgraduate Med 2007; 53(4):262-266

75. London P. The modes and morals of psychotherapy, (2nd edn.). New York: Hemisphere, 1985.

76. Fallot RD. Spirituality and religion in psychiatric rehabilitation and recovery from mental illness. International Review of Psychiatry 2001; 13(2):110-116.

77. Brooks RG, Koenig HG. Crossing the secular divide: government and faith-based organizations as partners in health. International Journal of Psychiatry in Medicine 2002; 32 (3):223-234.

78. Puchalski CM, Larson DB, Lu FG. Spirituality in psychiatry residency training programs. International Review of Psychiatry 2001; 13(2):131-138

79. Koenig HG. Religion, spirituality, and medicine: research findings and implications for clinical practice. Southern Medical Journal 2004; 97(12):1194-1200.

80. Levin JS, Larson DB, Puchalski CM. Religion and spirituality in medicine: research and education. Journal of the American Medical Association 1997; 278(9):792-793.

81. Matthews DA, McCullough ME, Larson DB, Koenig HG, Swyers JP. Greenwold Milano M. Religious commitment and health status: a review of the research and implications for family medicine. Archives of Family Medicine 1998; 7(2):1 18-124.

82. Moreira-Almeida A, Neto FL, Koenig HG. Religiousness and mental health: a review. Revista brasileira de psiquiatria 2006; 28(3):242250.

83. Koenig HG. Religion, spirituality, and medicine: how are they related and what does it mean? Mayo Clinic Proceedings 2001, 76(12):1189-1191.

84. Koenig HG, Cohen HJ. Spirituality across the lifespan. Southern Medical Journal 2006; 99(10):1 157-1158.

85. Garroutte EM, Goldberg J, Beals J, Herrell R. Spirituality and attempted suicide among American Indians. Social Science and Medicine 2003; 56(7):1571-1579

86. Galanter M. The concept of spirituality in relation to addiction recovery and general psychiatry. Recent developments in alcoholism 2008; 18:125-140.

87. Galanter M. Spirituality and addiction: A research and clinical perspective. American Journal on Addictions 2006; 15(4):286-292.

88. Koenig HG, George LK, Meador KG, Blazer Dg, Ford SM. Religious practices and alcoholism in a southern adult population. Hospital \& Community Psychiatry 1994; 45(3):225-231.

89. Rumbold BD. A review of spiritual assessment in health care practice. Medical Journal of Australia 2007; 186 Supplement:S60S62.

90. Sulmasy DP. A bio-psycho-social-spiritual model of care of patients at end of life. Gerontologist 2002; 42:24-33.

91. D'Souza RF, Rodrigo A. Spiritually augmented cognitive behavioural therapy. Australasian Psychiatry 2004; 12(2):148-152.

92. Puchalski C. Spirituality in health: the role of spirituality in critical care. Critical Care Clinician 2004; 20(3):487-504.

93. Longo DA, Peterson SM. The role of spirituality in psychosocial rehabilitation. Psychiatric Rehabilitation Journal 2002; 25(4):333340.

94. Koenig HG. Religion and medicine II: religion, mental health, and related behaviors. International Journal of Psychiatry in Medicine 2001; 31 (1):97-109.

95. Koenig HG. Religion and medicine III: developing a theoretical model. International Journal of Psychiatry in Medicine 2001; 31(2):199-216

96. Koenig HG. Religion and medicine IV: religion, physical health, and clinical implications. International Journal of Psychiatry in Medicine2001; 31(3):321-336.

97. Vaillant G. Positive emotions, spirituality and the practice of psychiatry. Mens Sana Monographs 2008; 6(1):48-62.

98. Vaillant G. Spiritual evolution: A scientific defense of faith. New York: Broadway Books, 2008.

99. Anandarajah G. The 3H and BMSEST Models for Spirituality and Multi-cultural Whole-Person Medicine. Annals of Family Medicine 2008; 6:448-458.

100. Flannelly KJ, Galek K, Ellison CG, Koenig HG. Beliefs about God, Psychiatric Symptoms, and Evolutionary Psychiatry. Journal of Religion and Health 2009; 48(1) DOIC10.1007/s10943-009-9244-z.

101. Flannelly KJ, Koenig HG, Galek K, Ellison CG. Beliefs, mental health, and evolutionary threat assessment systems in the brain. The Journal of Nervous and Mental Disease 2007; 195(12):9961003.

102. King DE, Bushwick B. Beliefs and attitudes of hospital inpatients about faith healing and prayer. Journal of Family Practice 1994 39(4):349-352

103. Ancharsäter H, Stahlberg O, Larson T, Hakansson C, Jutblad S-B, Niklasson $L$, et al. The impact of ADHD and autism spectrum disorders on temperament, character and personality development. American Journal of Psychiatry 2006; 163(7):1239 1244.

104. Dell ML, Josephson AM. Working with spiritual issues of children Psychiatric Annals. 2006; 36(3):176-181.

105. Dew RE, Daniel SS, Goldstone DB, Koenig HG. Religion, spirituality, and depression in adolescent psychiatric outpatients. The Journal of Nervous and Mental Disease 2008; 196(3):247-251.

106. Dew RE, Daniel SS, Goldstone DB, MCCall WV, Kuchibhatla M, Schleifer $C$, et al. A prospective study of religion/spirituality and depressive symptoms among adolescent psychiatric patients. Journal of Affective Disorders 2009; doi:10.1016lj.jad.209.04.029

107. Kroll J, Erickson P. Religion and Psychiatry. Current Opinion in Psychiatry 2002; 15(5):549-554.

108. Breitbart W, Gibson C, Poppito SR, Berg A. Psychotherapeutic interventions at the end of life: focus on meaning and spirituality. Canadian Journal of Psychiatry 2004; 49(6):366-372.

109. Chen YY, Koenig HG. Do people turn to religion in times of stress? An examination of change in religiousness among elderly, medically ill patients. The Journal of Nervous and Mental Disease 2006; 194(2):114-120

110. Holt J. Psychiatry and spirituality at the end of life: A case report. Psychiatric Services 2004; 55(6):618-622.

111. Koenig HG, Hays JC, Larson DB, George LK, Cohen HJ, MCCullough ME, et al. Does religious attendance prolong survival? A six-year follow-up study of 3,968 older adults. The Journals of Gerontology. Series A, Biological Sciences and Medical Sciences. 1999; 54(7):M370-M376.

112. Pargament KI, Koenig HG, Tarakeshwar N, Hahn J. Religious coping methods as predictors of psychological, physical and spiritual outcomes among medically ill elderly patients: a two-year longitudinal study. Journal of Health Psychology. 2004; 9(6):713730.

1 13. Hathaway WL. Clinically significant religious impairment. Mental Health, Religion and Culture 2003; 6(2):1 13-129.

114. Hopkins B, Battin MP. Religion. In: Raddan, J. (ed.) The Philosophy of Psychiatry: A Companion. New York: Oxford University Press, 2004.

115. MCConnell KM, Pargament KI, Ellison CG, Flannelly KJ. Examining the links between spiritual struggles and symptoms of 
psychopathology in a national sample. Journal of Clinical Psychology 2006; 62(12):1469-1484.

116. Carter JH. Religion/spirituality in African-American culture: an essential aspect of psychiatric care. Journal of National Medical Association 2002: 94(5):371-375.

117. Keks N, D'Souza R. Spirituality and psychosis. Australasian Psychiatry 2003; 11 (2):170-171.

118. MCCullough ME, Larson DB. Religion and depression: a review of the literature. Twin Research 1999; 2(2):126-136.

119. Grucza RA, Przybeck TR, Spitznagel EL, Cloninger CR. Personality and depressive symptoms: A multi-dimensional analysis. Journal of Affective Disorders 2003; 74: 123-130.

120. Vaccaro B. Spirituality in the treatment of a man with anxiety and depression. Southern Medical Association 2007; 100(6):626-627.

121. Krisanaprakornkit T, Krisanaprakornkit W, Piyavhatkul N. Meditation therapy for anxiety disorders. [Online] In: The Cochrane Collaboration. (eds.) The Cochrane Library, Issue 2. Available from: http://www. thecochranelibrary.com; Wiley \& Sons, 2007.

122. Huguelet P, Mohr S, Borras L, Gillieron C, Brandt P-Y. Spirituality and religious practices among outpatients with schizophrenia and their clinicians. Psychiatric Services 2006; 57(3):336-372.

123. Mohr S, Brandt P-Y, Borras L, Gillieron C, Huguelet P. Toward an integration of spirituality and religiousness into the psychosocial dimension of schizophrenia. American Journal of Psychiatry 2006 163:1952-1959

124. Mohr S, Gillieron C, Borras L, Brandt P, Huguelet P. The Assessment of Spirituality and Religiousness in Schizophrenia. Journal of Nervous and Mental Disease 2007;195(3):247-253.

125. Le o FC, Neto FL. Spiritual practices in an institution for mentally disabled. Revista de Psiquiatria Clínica 2007; 34(1) Supplement: 23-28.

126. King M, Jones L, Barnes $K$, Low J, Walker C, Wilkinson S, et al. Measuring spiritual belief: development and standardization of a Beliefs and Values Scale. Psychological Medicine 2006; 36(3):417425.

127. Katerndahl D, Oyiriaru D. Assessing the Biopsychosociospiritual Model in Primary Care: Development of the Biopsychosociospiritual Inventory (BioPSSI). International Journal of Psychiatry in Medicine 2007;37(4):393-414.

128. Barnett KG, Fortin AH. Spirituality and medicine. A workshop for medical students and residents. Journal of General Internal Medicine 2006; 21 (5):481-485.

129. Fazzio L, Galanter M, Dermatis H, Levounis P. Evaluation of medical student attitudes toward alcoholics anonymous. Substance Abuse 2003; 24(3):175-185.

130. Graves DL, Shue CK, Arnold L. The role of spirituality in patient care: incorporating spirituality training into medical school curriculum. Academic Medicine 2002; 77(1):1167.

131. Musick DW, Cheever TR, Quinlivan S, Nora LM. Spirituality in medicine: A comparison of medical students' attitudes and clinical performance. Academic Psychiatry 2003; 27(2):67-73.

132. Puchalski CM, Larson DB, Lu FG. Spirituality courses in psychiatry residency programs. Psychiatric Annals 2000; 30(8):543-548.

133. Targ E. A curriculum on spirituality, faith, and religion for psychiatry residents. Psychiatric Annals 1999; 29(8):485-488.

134. Coyle BR. Twelve myths of religion and psychiatry: Lessons for training psychiatrists in spiritually sensitive treatments. Mental Health, Religion and Culture 2001; 4(2):149-174

135. Lev-Ran S, Fennig S. Points to ponder regarding contemporary psychiatric training in Israel. The Israel Journal of Psychiatry and
Related Sciences 2007; 44(3):187-193

136. Grabovac A, Clark N, McKenna M. Pilot study and evaluation of postgraduate course on "The interface between spirituality, religion and psychiatry". Academic Psychiatry 2008; 32(4): 332337.

137. Grabovac AD, Ganesan S. Spirituality and religion in Canadian psychiatric residency training. Canadian Journal of Psychiatry 2003; 48(3):171-175.

138. Post SG, Puchalski CM, Larson DB. Physicians and patient spirituality: professional boundaries, competency, and ethics, Annals of Internal Medicine 2000; 132 (7):578-583

139. Puchalski C. Spirituality and health: The art of compassionate medicine. [Online] Hospital Physician. 2001; Available from www.turner-white.com, pp. 30-36.

140. Brody H. The healer's power. New Haven: Yale University Press, 1992.

141. Handzo G, Koenig HG. Spiritual care: whose job is it anyway? Southern Medical Journal 2004; 97(12):1242-1244.

142. Winslow GR, Wehtje-Winslow BJ. Ethical boundaries of spiritual care. Medical Journal of Australia 2007; 186(Supplement):S63-S66

143. Loewenthal KM. Mental Health and Religion. London: Chapman and Hall, 1995.

144. Sexton R, Sorlie T. Use of traditional healing among Sami psychiatric patients in the north of Norway. International Journal of Circumpolar Health 2008; 67(1):135-146.

145. Wig NN. Mental health and spiritual values: $A$ view from the East. International Review of Psychiatry 1999; 11 (2):92-96.

146. Yip K. Taoism and its impact on mental health on the Chinese communities. The International Journal of Social Psychiatry 2004;50(1):25-42

147. Agara AJ, Makanjuola AB. Morakinyo O. Management of perceived mental health problems by spiritual healers: a Nigerian study. African Journal of Psychiatry 2008; 11 (2):113-118.

148. Catanzaro AM, Meador KG, Koenig HG, Kuchibhatla M, Clipp EC. Congregational health ministries: a national study of pastors' views. Public Health Nursing 2007; 24(1):pp. 6-17.

149. Koss-Chioino JD. Spirit healing, mental health and emotion regulation. Zygon. 2005; 40(2): 409-421.

150. Krippner S. Humanity's first healers: psychological and psychiatric stances on shamans and shamanism. Revista de Psiquiatria Clínica 2007; 34(Supplement):16-22.

151. Weaver AJ, Flannelly KJ, Larson DB, Stapleton CL, Koenig HG. Mental health issues among clergy and other religious professionals: a review of research. The Journal of Pastoral Care and Counseling 2002; 56(4):393-403

152. Weaver AJ, Flannelly LT, Flannelly KJ, VandeCeek L, Koenig HG, Handzo GA. A 10-year review of research on chaplains and community-based clergy in 3 primary oncology nursing journals: 1990-1999. Cancer Nursing 2001; 24(5):335-340.

153. Kourie C. Postmodern spirituality in a secular society. In: Du Toit C.W., Magson C.P. (eds.). Secular spirituality as a contextual critique of religion. Pretoria: RITR, 2006.

154. Van den Berg J, Van den Berg J. Mental and spiritual health: Crossroads between brain and soul. Practical Theology in South Africa 2007; 22(2):192-208.

155. Krause N. Religion and Health: Making Sense of a Disheveled Literature. Journal of Religion and Health DOI 10.1007/s10943010-9373-4; $2011 ; 50: 20-35$

156. Maslow AH. Motivation and personality. New York: Harper; 1954.

157. Traditional Health Practitioners Act (No. 35 of 2004). Cape Town: Government Printer, Government Gazette. No 29034, 21 July 2006 